\title{
Desigualdades, territorios y vulnerabilidades en el desarrollo de América Latina (1990-2015) ${ }^{1}$
}

\section{Inequalities, Territories and Vulnerabilities in the Development of Latin America (1990-2015)}

\section{Desigualdades, territórios e vulnerabilidades no desenvolvimento de América Latina (1990-2015)}

\section{Esther Iglesias Lesaga ${ }^{2}$}

Investigadora Titular Instituto de Investigaciones Económicas, UNAM (México D.F.) estherb@unam.mx

\section{José Ramón Carmona Motolinia ${ }^{3}$}

Profesor en la Facultad de Estudios Superiores Acatlán, UNAM (México D.F.)

ramoncm@comunidad.unam.mx

1 Este artículo es producto del proyecto de investigación Revisión de las teorías de la región, dirigido por la doctora Esther Iglesias Lesaga en el IIEc (UNAM). La información empleada en la elaboración de este trabajo se recolectó entre el 30 de enero y el 26 de febrero del 2016.

2 Docteur en Histoire.

3 Maestro en Estudios Latinoamericanos. 


\title{
Resumen
}

Este artículo plantea repensar las desigualdades y vulnerabilidades en diferentes territorios y en las diversas coyunturas que adquiere el desarrollo de Latinoamérica en el período 1990-2015. Se despliega un análisis de tipo teórico sobre la temática y posteriormente se implementa el estudio a partir de ciertos indicadores aplicados para algunos territorios de América Latina. El tema se organiza en tres partes. La primera de ellas trata los problemas de desigualdad, desarrollo, vulnerabilidad y democracia a nivel teórico. En la segunda parte analizamos las temáticas de crecimiento y desempleo en la región latinoamericana durante el período de análisis. Por último, las vulnerabilidades generadas por la desigualdad son contempladas a partir de los conceptos de crecimiento económico y desarrollo. Las reflexiones finales cierran este análisis y plantean nuevas interrogantes sobre el tema.

Palabras clave: desigualdades; vulnerabilidades; territorios; desarrollo; América Latina.

\begin{abstract}
This essay proposes rethinking inequalities and vulnerabilities in different territories and various situations which acquires the development of Latin America in the 1990-2015 period. A theoretical analysis on the subject is presented, and subsequently the study is implemented based on certain indicators applied to some territories of Latin America. The topic is organized into three parts. The first one addresses the issues of inequality, development, vulnerability and democracy at the theoretical level. In the second part, we analyze the problems of growth and unemployment in Latin America during the period of analysis. Finally, the vulnerabilities generated by inequality are referred from the concepts of economic growth and development. Final reflections close this analysis and propose new questions about the topic.
\end{abstract}

Keywords: inequalities; vulnerabilities; territories; development; Latin America.

\section{Resumo}

Este artigo tenta repensar as desigualdades e vulnerabilidades em diferentes territórios, e em diversas conjunturas do desenvolvimento de América Latina, no período 1990-2015. Constrói-se uma análise de tipo teórico, e posteriormente se implementa um estudo com indicadores aplicados para alguns territórios de América Latina. O artigo se organiza em três partes: a primeira, aborda no nível teórico, os problemas da desigualdade, desenvolvimento, vulnerabilidade e democracia. A segunda, analisa as temáticas de crescimento e desemprego na região, durante o período estudado. Finalmente, as vulnerabilidades surgidas pela desigualdade, são tratadas desde os conceitos de crescimento econômico e desenvolvimento. As reflexões finais propõem novos interrogantes sobre o tema.

Palavras-chave: : desigualdades; vulnerabilidades; territórios; desenvolvimento; América Latina.

Este trabajo está bajo la licencia Creative Commons Attribution 3.0

¿Cómo citar este artículo? / How to quote this article?

Iglesias-Lesaga, Esther y José Carmona-Motolinia. «Desigualdades, territorios y vulnerabilidades en el desarrollo de América Latina (1990-2015)». Sociedad y economía, No. 31 (Julio - Diciembre 2016): 123-148. 


\section{Introducción}

En las sociedades latinoamericanas contemporáneas se le otorga al crecimiento económico un papel determinante. A mediados del siglo pasado las preocupaciones teóricas para disminuir las desigualdades se hacen manifiestas: la teoría de Kuznets fue una de ellas. En algunos espacios regionales como el que hoy nos ocupa, Latinoamérica, el problema adquirió singulares características y la búsqueda de una distribución más equitativa de la riqueza se persiguió a partir del aumento del crecimiento económico. En el decenio de 1980, la llamada década del 'aprendizaje doloroso', el modelo de desarrollo económico para la región se asentaba básicamente en la alta renta producida por los recursos naturales, con apoyo del crédito externo y engrosando los déficits fiscales: "América Latina prolongó con inercia un patrón de desarrollo poco creativo, incapaz de lograr convergencia de crecimiento y equidad" (Fajnzylber 1991, 11).

En lo que hace a este espacio, históricamente caracterizado por las extremas desigualdades, es necesario señalar que en la actualidad muchas de estas se han enquistado como rasgos inherentes a nuestras formaciones socioculturales.

Por otra parte, ya a comienzos de este siglo Piketty (2014) ha demostrado al analizar el fenómeno - para un período de larga duración- cómo, después de un proceso de declive de la desigualdad hasta la década de 1970, en la actualidad se han incrementado las diferencias en la distribución del ingreso, especialmente en los países más desarrollados.

Emplear el coeficiente de Gini para calcular la desigualdad en esta región ni siquiera alcanzaría para percibir los graves problemas que hoy atraviesa la población a partir del aumento del comercio informal, única fuente de ingresos para quienes no existen espacios en los empleos formales ${ }^{4}$. De todas maneras, abarcar la totalidad del abanico de problemas que generan los diversos tipos de desigualdades en los territorios latinoamericanos es una tarea que escapa a los límites de este trabajo. Por ello, solo escogemos determinados indicadores, como el empleo formal e informal, los cuales reflejan apenas ciertos ángulos del problema que hoy presentamos. Las desigualdades entre los grupos sociales que se amplían dando paso a la generación de bolsones de desigualdad territorial (Iglesias 2014) y que se expresan en función de diferentes dimensiones como la social y la económica son otros temas abordados. Aunque la educación es indiscutiblemente el tronco mayor de los problemas enunciados, el trabajo no tiene como objetivo proponer planes alternos a los vigentes para una nueva manera de encarar el desarrollo sino apenas desplegar aquellos indicadores que hacen a las tradicionales desigualdades y proponer algunas categorizaciones para las nuevas desigualdades que hoy se multiplican en nuestra región.

La densidad del problema que nominamos 'un ausente sin aviso', es decir el desarrollo sostenible, no nos permite detenernos en el análisis que amerita esta temática,

4 Debido a los limitados alcances para detectar la desigualdad socioeconómica dejaremos a un lado algunos coeficientes para medir la desigualdad, como por ejemplo el ya tradicional de Gini ya que, en este caso, solo evalúa los ingresos de los individuos, pero no tiene en cuenta todo aquello que abarca la categoría de bienestar humano: la salud, la inestabilidad en el empleo o la alta tasa de desempleo y la posibilidad de no poder cubrir las cuotas de renta o hipoteca de una vivienda, las cada vez más difíciles condiciones para pagar las colegiaturas de una educación terciaria, son algunos ejemplos de los que no están ausentes algunos países desarrollados como en el caso de Estados Unidos y la mayoría de los países de América Latina. 
pero sí tener presente que ello es prioritario para crear nuevos planes de desarrollo. No obstante, se considerarán algunos elementos en relación con la dimensión ambiental del desarrollo que hemos hallado sobre todo al analizar los proyectos de inversión que actualmente captan determinados espacios de Latinoamérica.

Para el constructo que sirve como base de este ensayo, se han entrelazado determinados elementos de orden cuantitativo y también cualitativo, y a su vez se han considerado algunas dimensiones y variables ad hoc en el estudio de las transformaciones producidas en los grupos sociales que habitan estos espacios.

\section{Primera parte}

\section{Los senderos de la desigualdad}

\section{Desigualdad y desarrollo}

Hasta la década de 1970, los países más industrializados habían mantenido un nivel de crecimiento económico significativo que les permitió reducir la desigualdad en la distribución de la riqueza. Sin embargo, Piketty (2014) ha aportado evidencia empírica que muestra la tendencia al aumento del fenómeno después de ese período. De acuerdo con este autor, el incremento de la desigualdad se deriva, entre otros elementos, de que en un régimen de crecimiento económico lento la riqueza histórica (obtenida, sobre todo, a través de la herencia), adquiere gran importancia "ya que solo se necesita un pequeño flujo de nuevos ahorros para aumentar el stock de riqueza de manera constante y de forma sustancial" (Piketty 2014, 28).

El concepto de desarrollo que predominó durante el período de la segunda posguerra simbolizó una articulación de diferentes elementos, según el contexto de las naciones en que se planteó. En diversos países del mundo se formularon modelos de desarrollo económico, a fin de integrar, en función de las políticas públicas, ciertos aspectos económicos y sociales relevantes para la sociedad desde una perspectiva nacional (Touraine 2001, 33). No obstante, a través de diferentes etapas históricas este concepto se ha interpretado de distintas maneras, y a su vez, se ha enriquecido con varios elementos que se suman a su propia naturaleza polisémica.

A pesar de haber favorecido amplios procesos de expansión económica en diversas regiones del mundo, existen algunos ejemplos de cómo el desarrollo puede llevar al aumento de la pobreza y la vulnerabilidad, además de poner en riesgo el porvenir de las civilizaciones modernas (Brundtland 1987).

\section{Globalización, desarrollo y desigualdad}

La desigualdad es uno de los fenómenos que ha acompañado los procesos de desarrollo económico y social en las sociedades modernas. Entendemos la desigualdad no solo como un fenómeno complejo (Reygadas 2004, 24), sino como un concepto polisémico -pues además de que se pueden identificar diversos factores que intervienen en su reproducción también existen distintos tipos de desigualdadesel cual hace referencia a las diferencias en el acceso a bienes y recursos que pueden obtener los agentes en el proceso de apropiación y aprovechamiento de las oportunidades que genera una sociedad determinada. Esta se ha convertido en una de las principales inquietudes para algunos organismos internacionales como el Banco Mundial y la Organización para la Cooperación y el Desarrollo Económicos (OCDE). En todo caso, sus planteamientos sobre este tema actúan a manera de 'fantasma 
distractor' para ocultar los graves problemas del crecimiento económico en determinados territorios de economías extractivas que destruyen las posibilidades de un desarrollo sostenible 5 . En este trabajo la noción de territorio se refiere al espacio caracterizado como la región económica vinculada a la globalización, el cual adquiere una nueva dinámica derivada de las características del capitalismo mundial. Como señalan Iglesias y Muñoz-Cota, "este proceso también provoca que se acentúen las desigualdades regionales en aquellos espacios marginados por su falta de competitividad dentro de la economía globalizada" $(2010,199)$.

De ese modo, la OCDE le dedica un estudio al fenómeno de la desigualdad en la distribución del ingreso y la riqueza a partir de las décadas de 1980 y 1990, y afirma que se extendió de manera significativa en los países miembros de la organización. Durante la primera década del siglo XXI la desigualdad entre ricos y pobres se amplió no solamente en países como Estados Unidos o Israel, sino también en países que tradicionalmente registraban una baja desigualdad como Alemania, e incluso en países del norte de Europa occidental como Dinamarca, Finlandia y Suecia (OCDE 2011, 25). La polarización en la distribución de la riqueza y los efectos de la desigualdad en estos países ha dado pie a diversos análisis a lo largo de las últimas décadas ${ }^{6}$.

No obstante, y al mismo tiempo que eso ocurre, en otros espacios se han generado determinadas dinámicas sociales que multiplican las desigualdades a partir de elementos étnicos, de raza, género o clase y de acuerdo con las características históricas y culturales de las diversas sociedades.

En la otra cara de Jano, es decir en lo social, quizá es donde se perciban con mayor claridad las escisiones de este crecimiento desordenado y desequilibrado. Sin embargo, la intensidad de las desigualdades ha dependido en gran medida del nivel alcanzado en cuanto a la intervención del Estado en las esferas económica y social de cada país?.

A su vez y "a medida que el mundo se vuelve más integrado la dimensión global de la desigualdad es probable que se vuelva cada vez más relevante" (Milanovic 2012, 2). También para este autor, es necesario incorporar nuevas conceptualizaciones de desigualdad que se han desarrollado en estas últimas seis décadas: a) la desigualdad entre las naciones del mundo, b) la inequidad o desigualdad y c) la desigualdad en el mundo, que es de hecho el concepto más importante a términos del individuo: no todos los habitantes de los países desarrollados tienen el ingreso promedio que tienen los habitantes de Estados Unidos, ni tampoco todos los chinos tienen el

5 En apariencia se conoce poco sobre el extractivismo y la coacción extraeconómica aplicada en determinada mano de obra en varios territorios del continente africano por algunos capitales provenientes de Asia. Para el caso de América Latina y el Caribe, Espinasa, Marchán y Sucre (2015) señalan que ciertos países de la región se han convertido en exportadores de materias primas, energía y minerales debido a la alta demanda de estos productos en países de Asia. Esta situación puede afectar las perspectivas de un desarrollo sostenible en países como Venezuela y Argentina, en tanto que se han convertido en exportadores de grandes volúmenes de petróleo crudo.

6 Algunos analistas sostienen que la clase media de Alemania se redujo dado que el porcentaje de la población que pertenecía a este sector alcanzaba 65\% en 1997 y en 2012 disminuyó a 58\% (Koch y Papaleo 2012, 2).

7 De tal manera, Stiglitz (2015) ha criticado el aumento de la desigualdad señalando que en vez de aplicar políticas regresivas el gobierno de Estados Unidos debe aumentar la demanda y el empleo, para incentivar la economía. Y agrega que la desigualdad tendrá un costo muy alto porque la desigualdad económica se traduce inevitablemente en desigualdad política. 
ingreso promedio de China ${ }^{8}$. Según el autor, en estos últimos dos siglos se ha producido un macrodesarrollo y esto solo se puede explicar si el principal determinante de los ingresos de una empresa es la ubicación. Tendríamos que preguntarnos, a partir de la ubicación, quiénes son los de abajo. A su vez, extenderíamos esta interrogación para estudiar si la mayoría de la desigualdad global se debe a diferencias en la ubicación: “... ¿Podemos tratar la ubicación, y por lo tanto la ciudadanía, como una renta o un premio (u observarla como una pena)? ¿Es la ciudadanía -que pertenece a un país determinado, lo más a menudo a través del nacimiento-, algo que nos da por sí mismo el derecho de mayores ingresos?" (Milanovic 2012, 25).

A partir de esta reflexión sería posible concluir que la globalización lleva a diferentes niveles en el crecimiento y desarrollo que permitirían extender otros límites para reflejar nuevas desigualdades tales como las que se generan únicamente en función del país de origen del individuo. Aunque este fenómeno del territorio de nacimiento no es nuevo en la historia (confróntese, por ejemplo, las migraciones forzadas de grandes oleadas de la población africana durante el esclavismo), sí es significativo el peso que adquieren determinados y nuevos territorios alternos a los del pasado en tanto que centros de expulsión. En uno y otro momento histórico el escenario espacial latinoamericano ha servido como focos centrífugos o centrípetos. En la actualidad, una parte importante de su población se ve precisada a migrar en la búsqueda por la sobrevivencia económica.

Con base en estos elementos y repensando la vulnerabilidad, se puede plantear que el proceso de agudización de las desigualdades que ocurre en función de la globalización económica ha generado, a su vez, un ensanchamiento de las vulnerabilidades entre los sectores de la población de Latinoamérica. La noción de vulnerabilidad es entendida como "la incapacidad de una persona o de un hogar para aprovechar las oportunidades disponibles en distintos ámbitos socioeconómicos, para mejorar su situación de bienestar o impedir su deterioro" (Kaztman 2000, 279). De ese modo, esta afecta a amplios grupos sociales que no solamente estarían en riesgo de caer en situación de pobreza, sino que cada vez están más expuestos a los choques socioeconómicos debidos a la multiplicación de factores vinculados a la inestabilidad en el empleo y la disminución de la calidad del mismo. Se trata de un fenómeno que aparece en tanto que el crecimiento que se da con la globalización ocurre en función de la incorporación o la expulsión de territorios de la economía global (Sassen 2015, 27).

\section{Desigualdad y democracia}

En otra dimensión del problema, a lo largo de las primeras décadas del siglo XXI se constata que la desigualdad socioeconómica se refleja también en los países en los que el Estado de bienestar todavía mantiene cierta vigencia: los valores de la población en relación con la misma comienzan a modificarse. No obstante, el fenómeno de la desigualdad no solo comprende aspectos económicos y sociales, su análisis también supone incorporar determinados ángulos políticos y culturales (Therborn 2011, 4).

8 "La desigualdad global puede reducirse a través de altas tasas de crecimiento de los países pobres. Esto requiere una aceleración del crecimiento de los ingresos de los países pobres, y por supuesto continuar con altas tasas de crecimiento en la India, China, Indonesia, etc." (Milanovic 2012, 26). 
Una de las cuestiones que han adquirido relevancia a lo largo de las últimas décadas está referida a la dimensión política de la desigualdad, dado que el modelo de democracia liberal -que supone una ciudadanía universal- se ha difundido en diversas regiones del planeta. A partir de las décadas de 1980 y 1990, este modelo se caracterizó por la instauración de un proceso de democratización formal de la vida política en diversos países de América Latina y Europa oriental, así como en algunos países africanos. No hay que olvidar que la globalización económica exigió un adelgazamiento del aparato del Estado9 el cual debía ser acompañado de una democratización y que en América Latina se puso de manifiesto.

En estos últimos decenios, a medida que las democracias se fortalecen en espacios como los latinoamericanos, a diferencia de lo que ocurrió en los países asiáticos, poco a poco comienzan a desarrollar un fuerte presidencialismo. Este síndrome no solo es la respuesta al proceso de adelgazamiento del aparato del Estado que ha sido transformado por la globalización, sino que se debe también a los resabios caudillistas y caciquiles que emergieron durante toda la primera mitad del siglo XIX, momento previo y posterior a sus independencias.

Sin embargo, en torno a dicho modelo han surgido diversos problemas no solo en estos países, sino también en aquellos donde la llamada democracia liberal se habría ya instaurado desde comienzos del siglo XX. La igualdad considerada en términos políticos no supone la disminución de la desigualdad social y económica, dado que se contrapone con la concepción del Estado liberal-democrático (Requejo 1990) que ha proliferado en distintas regiones del mundo.

\section{Segunda parte}

\section{Las manifestaciones del desarrollo en América Latina}

\section{Ayer y hoy: las brechas en el crecimiento}

Los cambios económicos y sociales ocurridos en Latinoamérica de los años de 1950 a los de 1970 ampliaron las inequidades que ya existían en estas sociedades: el modelo de desarrollo económico que entonces se aplicó sirvió para fortalecer las desigualdades. Años más tarde, a principios de la década de 1980, la crisis económica forzó a los países de la región a aplicar políticas de "ajuste" que los obligaron a realizar grandes transferencias de recursos al exterior ${ }^{10}$. Con la aplicación de las políticas neoliberales, fundamentalmente centradas en la estabilización económica, en la región nacen los primeros procesos de liberalización comercial y privatización de las empresas públicas. Todo ello, en un contexto caracterizado por una fuerte oposición al intervencionismo estatal que favoreció la desregulación económica. Latinoamérica y sus diferentes territorios deben considerarse, sin duda alguna, como un ejemplo paradigmático.

9 En varias naciones de América Latina se produjo un debilitamiento del Estado que: "no solo afectó al gasto, a sus instituciones regulatorias o a la empresa pública, sino que provocó un fuerte golpe a las finanzas públicas, al reducir las cargas fiscales a la riqueza y favorecer la evasión sistemática de impuestos, con la ayuda fundamental de los paraísos fiscales y el reforzamiento del secreto bancario" (Dabat 2010, 43).

10 De 1980 a 1996 la deuda externa de América Latina se elevó de 257 a 657 mil millones de dólares (Schatan 1998, 26). 
En cuanto a la distribución de la riqueza y a diferencia de como ocurrió en los países desarrollados, los cambios económicos en la región durante el periodo señalado no produjeron una convergencia en torno a la reducción de la desigualdad. En 1970 el 1\% más rico ganaba 363 veces más que el 1\% más pobre del total de la población de Latinoamérica. Sin embargo, la brecha se redujo a principios de la década de 1980: descendió a 237 veces lo obtenido por el 1\% más rico. A partir de esta década se revirtió el proceso de disminución de la desigualdad que se registró en algunos países durante los años de 1970 y este fenómeno se aceleró a principios de los de 1990: la tendencia de la desigualdad en la distribución de la riqueza comenzó a acentuarse nuevamente y ya en 1990 el $1 \%$ más rico ganaba 361 veces más que el 1\% más pobre, mientras que en 1995 la diferencia se incrementó a 417 veces (Londoño and Székely 1997, 11-12). En todo caso y en el momento en que estos autores publican su trabajo, aún no existían las enormes desigualdades que hoy se han abierto paso entre el cada vez más reducido grupo de individuos más ricos en el mundo y en el espacio latinoamericano que representan una diferencia aún más aguda entre ellos y los individuos más pobres.

\section{Efectos de las reformas económicas de la década de 1990}

Las reformas económicas implementadas a partir de la década de 1990 por los gobiernos de las naciones latinoamericanas favorecieron ciertos cambios en el tejido productivo que llevaron a la disminución de las exportaciones tradicionales. Estas se han ido reduciendo frente a la exportación de materias primas (minerales y energía") y de algunas manufacturas, que han elevado su participación en las distintas subregiones ${ }^{12}$, pero que en muchos casos significan realmente la exportación de manufacturas elaboradas con mano de obra barata, a pesar de que el modelo exportador haya generado cierta elevación del producto interno bruto (PIB) en estas economías ${ }^{13}$.

Desde nuestro punto de vista, considerar ciertos cambios estructurales que están en proceso de construcción en los territorios de los países que se conciben como parte de América Latina en tanto que marco de referencia de los procesos de desarrollo puede resultar desacertado. Estos cambios muestran elementos dentro de la realidad económica, social, cultural y política de nuestras sociedades, con un débil sustrato respecto a lo que podría considerarse como un 'nuevo desarrollo'. El desarrollo no solamente implica el establecimiento de diversos elementos técnicos

11 En el período del 2000 al 2010, la exportación de minerales de los países de América Latina y el Caribe hacia los países asiáticos se incrementó en un promedio de $11 \%$ anual, mientras que las exportaciones al resto del mundo solamente alcanzaron un crecimiento por año de $4 \%$ (Espinasa, Marchán y Sucre 2015, 11).

12 En el 2006 las exportaciones manufactureras de Centroamérica y México representaban 49,6\% y $75,9 \%$ respectivamente, del total de sus exportaciones. En tanto que, el promedio de las exportaciones manufactureras de los países sudamericanos fue de $29 \%$ en ese mismo año. No obstante, en ambos casos se trata de eslabonamientos hacia el exterior que no necesariamente crean encadenamientos internos relevantes (Ugarteche 2010, 65).

13 La tasa de crecimiento del PIB total en América Latina y el Caribe osciló de 3\% a 5\% entre 1991 y 1997, registrando una fuerte caída en 1998 (2\%), hasta llegar a 0,5\% en 1999. No obstante, a comienzos de la década del 2000 el PIB creció nuevamente más de $4 \%$ cayendo posteriormente entre el 2001 y el 2003 (CEPALSTAT 2000-2015). 
aplicados a la economía en un espacio determinado, cuyo crecimiento permite una agregación selectiva de ciertos segmentos productivos al mercado regional o a los mercados mundiales, ni tampoco supone únicamente la incorporación de algunos sectores de la población -antes marginados- al consumo de determinados bienes, como ocurre actualmente en varios países de Latinoamérica.

Las 'oleadas de desarrollo económico' (Pérez 2009), se conciben como amplios procesos de transformación social, económica y tecnológica, que no solo favorecen la aparición de nuevos bienes que son producidos a partir de nuevas tecnologías. Este proceso implica la construcción de un terreno fértil para la asimilación de los cambios y su reproducción, en la medida que pueda avanzar el despliegue de las capacidades económicas, sociales y tecnológicas de los actores que operan en un territorio determinado ${ }^{14}$.

\section{El crecimiento económico de Latinoamérica en el siglo XXI}

La literatura producida por organismos multilaterales como la OCDE y la Comisión Económica para América Latina y el Caribe (CEPAL) destaca la importancia que ha tenido el crecimiento económico en América Latina durante la última década a raíz del aumento en sus exportaciones, aunque también señala los riesgos que estos países enfrentarán en el mediano y largo plazo si continúan con este modelo económico, ya que según afirman dichas instituciones la 'región' habría ya entrado en un período de desaceleración (OCDE-CEPAL 2013).

A pesar de la dinámica económica que se desplegó en los distintos espacios desde el año 2000, gran parte de los países de la región no han sido capaces de transformar sus estructuras productivas: sus territorios manifiestan mínimas diferencias en relación con la composición de los sectores de actividad económica, destacando la concentración de la población en actividades del sector terciario ${ }^{15}$.

El frágil dinamismo que registró la tasa de crecimiento del PIB de América Latina y el Caribe durante la década de 1990 se modificó ligeramente en el correr del siglo XXI. A partir del 2004 se manifestó un aumento superior a 5\% alcanzando un incremento de más de $6 \%$ en el 2010. Sin embargo, el aumento en la tasa de crecimiento del PIB registrado a partir del 2004 no ha generado procesos de encadenamiento productivo desde adentro que produzcan una activación económica sistémica, por ejemplo, en el sector manufacturero. En la etapa reciente, estas economías comienzan a registrar los efectos de la desaceleración económica mundial, sobre todo en los países que se han convertido en los principales productores de las exportaciones que consume China: en 2011 se observa un descenso en el crecimiento del PIB (de 4,2\% a 2,7\% en 2013). Las proyecciones elaboradas por la CEPAL pronosticaban que el crecimiento de la economía de nuestros países sería solamente de $1 \%$ en 2015. Lamentablemente la región de América Latina y el Caribe sufrió un decremento del -0,4\% para ese año. Se prevé que en 2016 su crecimiento apenas alcanzará el 0,2\% (CEPAL 2015).

14 En el enfoque aquí planteado no pretendemos acentuar el papel del cambio tecnológico y las mejoras en educación como únicos factores determinantes del desarrollo.

15 En promedio, en América Latina la población se concentra en las actividades del sector terciario que en el 2013 representó alrededor del 60\% (CEPALSTAT 2000-2015). 
En otro orden de problemas, tampoco se puede soslayar el perverso comportamiento del sector financiero en el creciente nivel de desigualdad social que hoy se extiende en una gran mayoría de los países y más allá de la región latinoamericana ${ }^{16}$.

Uno de los indicadores que desnuda con cierta claridad los orígenes de esta desigualdad es la tasa de desempleo en la región (gráfica l) que hacia 1991 representaba 7\% alcanzando $11 \%$ en 1999, 2002 y 2003. Después de esta etapa se observó un descenso en el porcentaje de desempleados, el cual se redujo a $10 \%$ en 2004 y $7 \%$ en 2008. No obstante, durante el período 2003-2010 no existió un proceso de diversificación productiva y la polarización entre los sectores más avanzados y los menos avanzados aún sigue vigente. Reiteramos: la dinámica económica que ha experimentado América Latina y el Caribe en diversos períodos no permite hablar de una convergencia sostenida ${ }^{17}$.

Gráfica 1. Tasa de crecimiento del PIB y tasa de desempleo en América Latina y el Caribe, 1991-2010

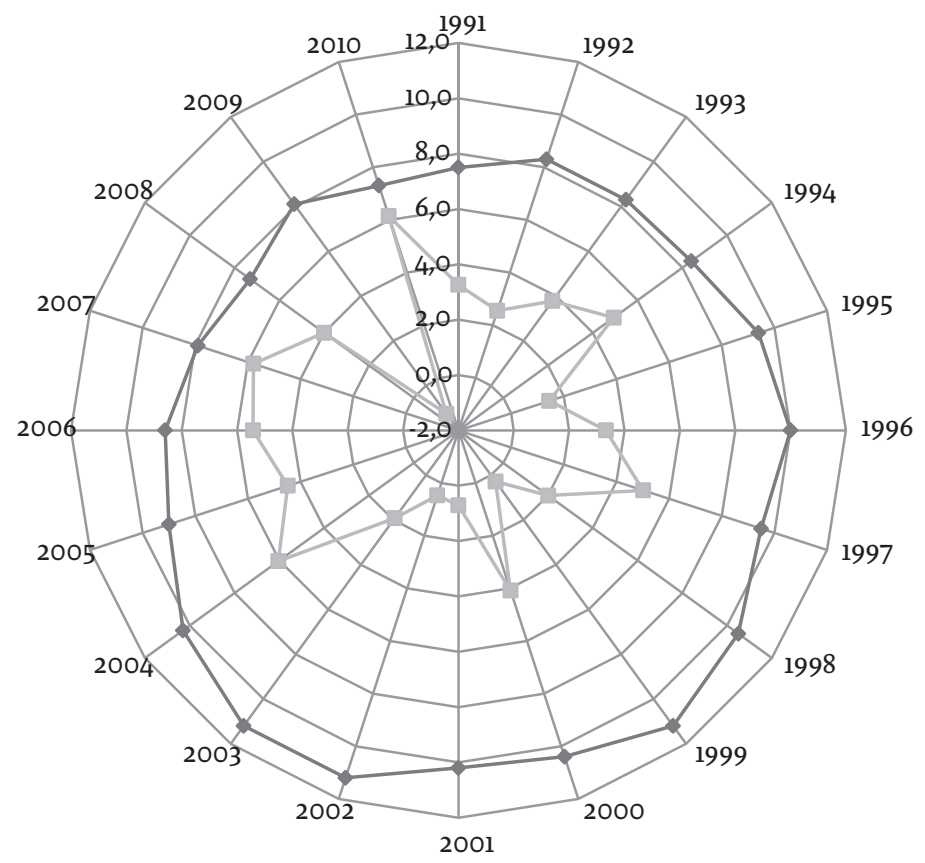

- Tasa de crecimiento del producto interno bruto (PIB) $\prec$ Tasa de desempleo

Fuente: elaborado a partir de datos de CEPALSTAT (2000-2015). Estadísticas e indicadores económicos y sociales.

16 Tal y como señala Stiglitz: "Nada influye más en el bienestar de la mayoría de los ciudadanos que el estado de la macroeconomía -si hay o no pleno empleo y crecimiento-. [Pero] la distribución de la renta raramente se menciona en macroeconomía" $(2015,303)$.

17 Así, el período de 2003 a 2010: "es excepcional y hay indicios de que en algunos países pueden resurgir los problemas en el sector externo [...] Las fases de convergencia tienden a coincidir con ciclos de acceso fluido al financiamiento o mejoras en los términos de intercambio; la dinámica posterior de los precios macroeconómicos, los desequilibrios que se acumulan en la cuenta corriente y la debilidad de la inversión (en términos de tasa y composición) preparan el terreno para una nueva etapa de divergencia" (CEPAL 2014, 64). 
En el 2013, la desigualdad en la distribución del ingreso sigue siendo significativa: el último decil de la población obtiene ingresos que representan 29 veces lo obtenido por el primer decil (CEPALSTAT 2000-2015). Lo anterior, en función de un entorno caracterizado por un lento crecimiento económico, que tuvo un período de auge a comienzos de este siglo.

Recordemos que a lo largo de la primera década del siglo XXI los modelos de crecimiento y desarrollo económico latinoamericanos han estado preocupados por medir no tanto las desigualdades generadas por los mismos, sino el fenómeno de la pobreza que ha venido ocultando el de las desigualdades y ha permitido la aplicación de 'soluciones con programas coyunturales ad hoc', para atenuar los problemas económicos y sociales de la población.

En tanto que las brechas que persisten en la estructura productiva de la mayoría de los países regionales reproducen la asimetría que ha existido desde décadas atrás entre los sectores de la economía con altos niveles de productividad respecto de aquellos de baja productividad; el proceso de concentración de la población urbana ocupada se da en aquellos sectores de baja productividad tales como por ejemplo el llamado sector informal (gráfica 2) que de hecho genera los bolsones de desigualdad territorial (Iglesias 2014) y que pretendemos desplegar en algunas de sus dimensiones.

Gráfica 2. Total de personas ocupadas en el área urbana del sector informal en América Latina*, 1990-2013.

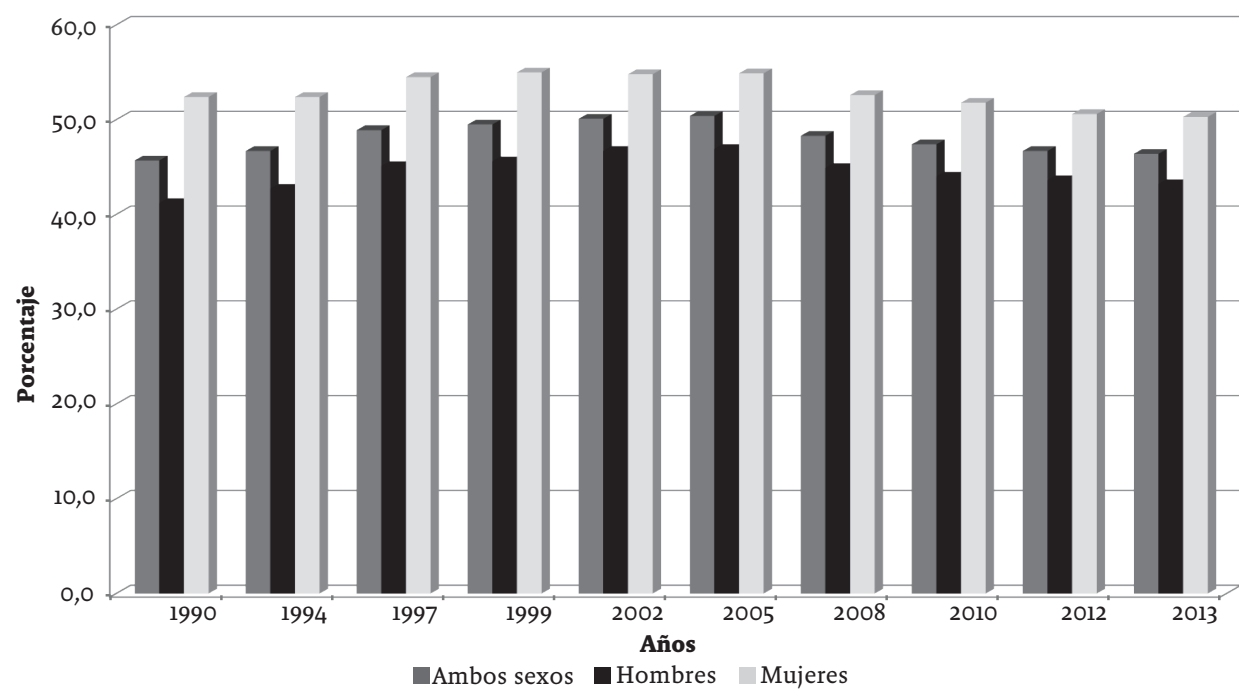

* Promedio simple.

Fuente: elaborado a partir de datos de CEPALSTAT (2000-2015). Estadísticas e indicadores sociales. Empleo. El número de países considerados varía en algunos años. 


\section{Tercera parte}

\section{Las nuevas vulnerabilidades de América Latina}

\section{Desigualdades y vulnerabilidades}

Las diferentes transformaciones económicas habidas en la región han acelerado las desigualdades especialmente dentro de los sectores medios de la sociedad: una mayor necesidad de reformas sociales para atemperar las brechas de la desigualdad en los sectores más marginales conlleva a su vez nuevas respuestas por parte de aquellas capas medias de la sociedad que sienten vulnerados sus derechos: el ejemplo arquetípico es el Brasil de la actualidad (2015).

La dimensión económica de la desigualdad no podría contemplarse sin tener en cuenta el indicador del desempleo que ya registraba una tendencia creciente desde la década de 1980, poco antes de la irrupción de la globalización económica, periodo donde ya muestra la gravedad de sus efectos.

Las décadas siguientes han manifestado que el patrón de desarrollo, además de poco creativo, no lograba convergencia entre crecimiento y equidad y era necesario cubrir déficits fiscales.

El desempleo debe ser visualizado también durante esta misma coyuntura de los años de 1980 tomando en cuenta el indicador que mide la incorporación masiva de la mano de obra femenina, especialmente aquella que contempla a las jóvenes a partir de los 15 años, y que irrumpe en el mercado laboral ${ }^{18}$. Para esos años las mujeres representaban $28 \%$ de la fuerza laboral y esta proporción se ha incrementado hasta 42\% en el 2015 (CEPALSTAT 2000-2015). La misma tendencia se manifiesta en algunos países de la Unión Europea, caso España, y en determinados países de América Latina observamos comportamientos diversos, aunque siempre con este indicador en aumento. Por ejemplo, en Argentina -país donde la fuerza laboral femenina ha venido desarrollando incrementos en sus tasas- el desempleo de mujeres jóvenes pasó de $13 \%$ a $24 \%$ entre 1991 y 2013, alcanzando cerca de $40 \%$ en 2003 . En otros países de la región, salvo México y Perú, donde la fuerza laboral femenina se incorpora más tardíamente para ese mismo período alcanza entre $12 \%$ y $23 \%$. Según datos de la Organización Internacional del Trabajo, Colombia es atípica ya que sobrepasa el 40\% en el año 2000 (OIT 2015a; 2015b).

En correspondencia con esta tasa de desempleo de las mujeres jóvenes, la de los hombres jóvenes sigue la misma tendencia. Salvo en algunos años y en determinados países, como el caso de Argentina, que alcanza para el período aquí señalado dos coyunturas significativas, y que a su vez corresponden al aumento de desempleo a escala nacional: en 1995 y 2003 la tasa de desempleo llega a 30\% y 33\% respectivamente (OIT 2015a, 2015b). En los casos de Colombia, Brasil, Chile, Perú y México, aunque las tendencias en cada país son semejantes los porcentajes son menores.

18 La Organización Internacional del Trabajo (OIT) señala que las mujeres tienden a ser excluidas en el recuento del desempleo, además de que son las que enfrentan mayores dificultades a partir de la discriminación y las barreras estructurales, sociales y culturales que les impiden salir en busca de un trabajo. 
Ninguna reflexión sobre los orígenes de las desigualdades en los procesos de crecimiento y desarrollo osaría presentarse sin tener en cuenta la educación. También al considerar este indicador aparece de manera nítida el proceso de mayor crecimiento, pero sin desarrollo de calidad: los niveles (grados) de escolaridad en algunos países latinoamericanos han aumentado considerablemente desde finales del siglo pasado hasta hoy. Este aumento de la escolaridad, en la gran mayoría de los casos, no se traduce en el crecimiento de calidad de la educación y muy por el contrario se observan deterioros aplastantes para algunos países que han instituido calendarios mínimos para la obtención de los niveles (grados) secundarios.

$\mathrm{Al}$ analizar una de las dimensiones más importantes de la desigualdad, seguiremos tomando un indicador 'mensurable' como es el desempleo, pero en este caso lo proyectamos según los niveles (grados) de escolaridad. El comportamiento que adquiere el indicador de desempleo es inverso en determinados países miembros de la OCDE. Si en Francia las tasas más altas de ocupación y desocupación corresponden respectivamente a los mayores y menores niveles de escolaridad (educación secundaria y secundaria superior), en el caso de otros países como México ocurre lo contrario: el desempleo continúa pero en menor medida para aquella población que tiene grados más bajos de escolaridad (escolaridad secundaria y secundaria superior) aunque es mayor para la población que obtiene niveles (grados) de escolaridad terciaria (gráfica 3).

Gráfica 3. Población desempleada por nivel de educación en Francia y México, 2000-2013.

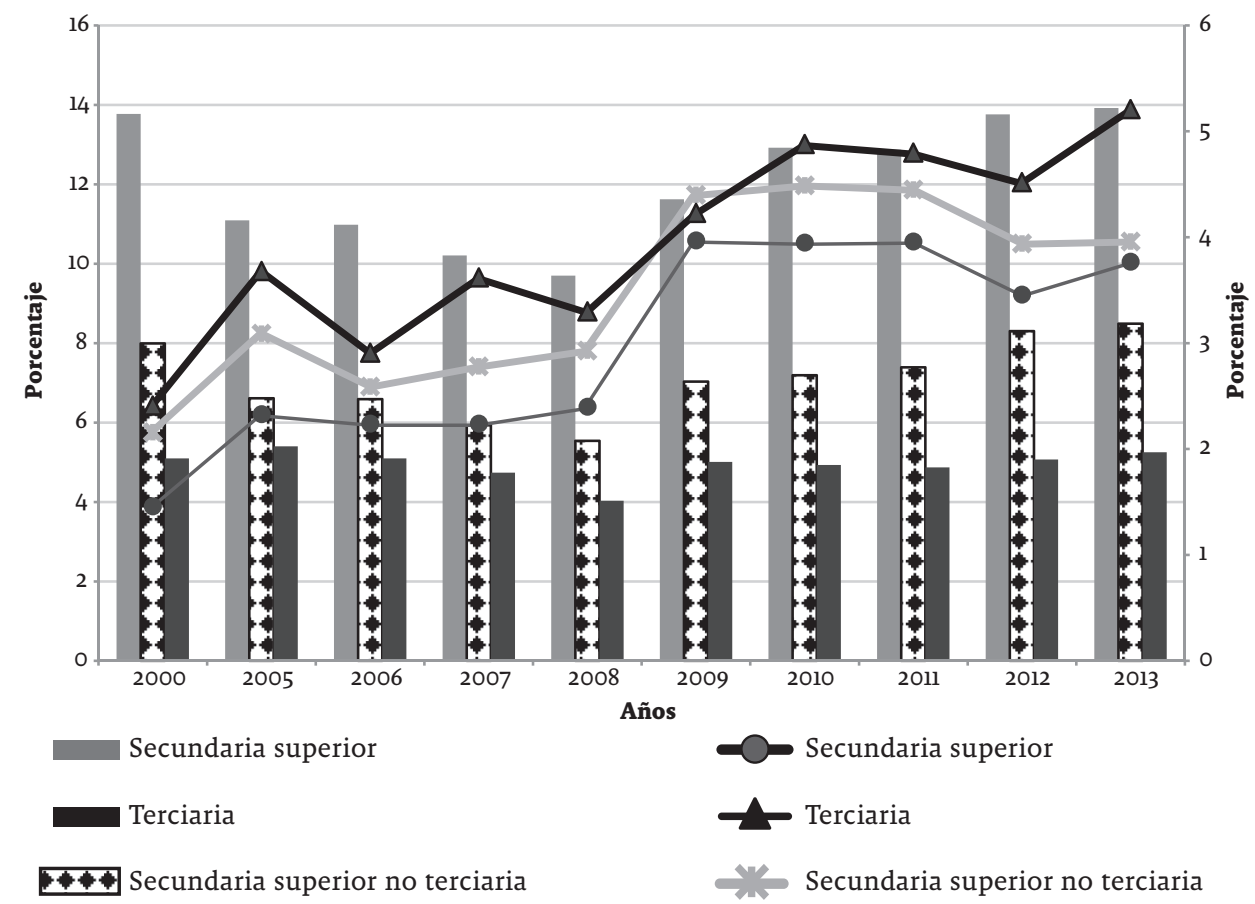

*Francia está en barras y México en líneas. Porcentaje de población entre 25 y 64 años.

Fuente: elaborado a partir de datos de la Organización para la Cooperación y el

Desarrollo Económicos (OCDE 2015). 
En todo caso, las desigualdades que se crean a escala global en función del acceso a la educación para los países desarrollados y quienes, como en la mayoría de los países de América Latina se encuentran en otras fases del desarrollo no se corresponde en unos y otros: Alemania tiene menos desempleados que cuentan con educación terciaria mientras que Francia continúa en este último decenio manteniendo una tasa de alrededor de $5 \%$. A su vez y en función de los frágiles niveles de crecimiento económico en los últimos años de una gran mayoría de los países latinoamericanos, muchos territorios no generan ni la suficiente cantidad de empleos ni la oferta importante para ocupaciones de cierta calificación. Pero, donde se abren nuevas desigualdades es sobre todo en algunos territorios de la región latinoamericana: es el caso de Brasil y México donde se observan comportamientos alternos. Mientras que en México es cada vez más difícil ampliar la oferta de empleo para quienes han alcanzado su educación terciaria (el desempleo pasó de 2,4\% en el 2000 a 5,21\% en $2013^{19}$ ), en el caso de Brasil el rápido ascenso de algunos grupos de los sectores medios ha permitido disminuir los niveles de desocupación de sus egresados terciarios de 3,2\% a 2,8\% para este mismo período (OCDE 2015). Por otra parte, no hay que olvidar -respecto de este último país- que algunas brechas en las desigualdades originadas por las diferencias en los salarios fueron cubiertas por un importante aumento de los mismos el que a su vez generó un nuevo crecimiento del mercado interno.

La creciente movilidad económica manifestada por los sectores medios en Brasil ha sido considerada como un ejemplo revelador: la desigualdad socioeconómica ha descendido por debajo de los registros que se tienen desde $1960^{20}$. Sin embargo, la desigualdad no solo persiste, sino que actualmente se expresa con fuerza en su dimensión territorial: el nordeste del país -a pesar de haber registrado un aumento en el ingreso promedio de 41,8\% (Tible 2013, 6)- sigue presentando enormes brechas en sus contrastes y desigualdades ${ }^{21}$. En otra dimensión territorial y continuando con el ejemplo de este mismo país recordemos que hacia 2014 las desigualdades se multiplican en su centro urbano más poblado, es decir São Paulo, el cual fue escenario de una de las peores crisis hídricas de la historia. Este fenómeno ha permitido reflejar con claridad un ángulo de la desigualdad territorial, que se expresa en función de las características orográficas y la infraestructura de las zonas habitadas por distintos grupos: en las zonas pobladas por sectores de altos ingresos que se ubican en áreas llanas, el equipamiento de las viviendas con instalaciones para almacenamiento de agua adecuado les facilita el acceso a este recurso esencial. Mientras tanto, las viviendas de los sectores de bajos ingresos se asientan en zonas de mayor altitud, donde la provisión de recursos como el agua depende de la inversión en sistemas

19 En el caso de México algunas fuentes generadas por los centros de investigación empresariales consideran que actualmente la tasa de desempleo alcanza alrededor de $11 \%$.

20 De acuerdo con algunos analistas, entre 2003 y 2011 alrededor de 39 millones de personas en Brasil pasaron a formar parte de las clases medias, que corresponde al sector de ingresos de entre $\$ 1.200$ y $\$ 5.174$ reales mensuales que equivalen a entre US\$588 y US\$2.540. Y en el 2011 este sector alcanzaba alrededor de 105,5 millones de personas (Neri 2012 en Tible 2013, 6).

21 Brasil ocupa el lugar 17 en el mundo y el cuarto en América Latina en desigualdad. Mientras que, en promedio el $10 \%$ más rico gana 40 veces más que el $10 \%$ más pobre. Asimismo, en relación con la estructura agraria 40,000 propietarios cuentan con el 50\% de la tierra cultivable (Freitas 2012, 139). En $30 \%$ de las viviendas del total nacional no se tiene acceso a servicios sanitarios, así como tampoco servicio de electricidad (Tible 2013, 9). 
hidráulicos que permitan su abastecimiento y acopio suficiente, los que no existen debido a la precariedad de las viviendas (Martín 2015, 2).

Los nuevos desarrollos tecnológicos incorporan cada vez en mayor medida a los territorios con significativos rezagos socioeconómicos. Actualmente, las economías del conocimiento marcan de manera significativa los espacios en los que se desarrollan. En este orden de problemas y reflexionando a partir de uno de los principales indicadores que, en la actualidad, mide niveles de desarrollo, se toma el ejemplo de las enormes brechas entre espacios de un mismo país: el caso de México es un ejemplo a considerar. Las desigualdades existentes entre los estados del norte, el centro y el occidente del país se observan a partir del índice de desarrollo de tecnologías de la información y la comunicación (IDTIC), el cual muestra que $47 \%$ de la población de México habita en entidades muy dispares y que se encuentran en niveles bajo o medio bajo en cuanto al desarrollo de TIC (Ruiz 2015, 42).

Hace algunas décadas los estudios que medían las desigualdades estaban a la zaga de aquellos que se preocupaban por las tasas de crecimiento como indispensables para conocer los niveles de desarrollo de un espacio. En la actualidad la temática de las desigualdades se encuentra entre los primeros lugares de las investigaciones acerca de los problemas del desarrollo. La desigualdad mayor dentro de la sociedad actual: la desigualdad generada por los niveles de ingreso se expresa en ciertos países latinoamericanos que a su vez son cuna de algunas de las fortunas más relevantes del mundo.

"La fuerza de la mundialización financiera podría conducir en este siglo que empieza a una concentración de capital aún más fuerte que todas las que se han observado en el pasado" (Piketty 2014, 686). Al hacer esta reflexión, Piketty se pregunta si algunos de los países más ricos del planeta serán finalmente poseídos por los países petroleros, o por China, o bien por sus propios 'billonarios' $(2014,686)$.

Para aterrizar en un ejemplo cercano de Latinoamérica, como es el caso de México, algunos autores en su última estimación de la concentración del ingreso, han encontrado que el decil de mayores ingresos aumentó 7,7 puntos porcentuales en México entre 1992 y $2012^{22}$ (Esquivel 2015, 17): en México se privilegió, hasta hace muy poco tiempo, la exención impositiva en el mercado accionario tanto como en los impuestos a las herencias ya que quien más percibe es quien recibe mayores beneficios. La fortuna de los 16 mexicanos más ricos (con capitales superiores a los 1.000 millones de dólares) representa entre 2011 y 2014 un promedio de $9 \%$ del PIB nacional (Esquivel 2015, 19-22).

A partir del adelgazamiento del Estado -el que a su vez 'delega' ciertos activos a precios bajísimos (como en el caso de Rusia)- crecen rápidamente las fortunas de aquellos empresarios que llegan a ocupar determinados espacios, como el de las telecomunicaciones, minería y otros: México es uno de los ejemplos más claros. Al poder económico estos grandes empresarios añaden el poder político para

22 Según estos mismos autores, entre 1996 y 2014 la fortuna promedio del grupo de los 16 mexicanos más ricos del país pasó de 1.700 a 8.900 millones de dólares (Esquivel 2015, 17).El valioso trabajo de Esquivel incluye proyecciones que dimensionan algunos de los ángulos de estas desigualdades: proyecta el total de trabajadores (alrededor de tres millones) que podrían ser contratados con salario mínimo por parte de los cuatro principales multimillonarios mexicanos con el rendimiento real de su riqueza (5\%) (Esquivel 2015, 31). Recordemos que el salario mínimo en México (ca. 4.30 dólares) es el más bajo de todos los países de la OCDE. 
conseguir que el Estado diseñe políticas públicas del crecimiento económico favoreciendo los intereses de ellos mismos que han amasado fortunas descomunales: las leyes tributarias redactadas ad hoc por asesores jurídicos podrían servir para estudiar otro de los orígenes del crecimiento acelerado de las desigualdades.

En esta nueva etapa se contempla ya un fortalecimiento de la monopolización de los mercados debido a la influencia recibida por tres grandes factores: el primero de ellos tiene que ver con la desregulación de las políticas económicas que a partir del Estado garantizaban 'cierta competencia'; en segundo término, la expansión geométrica de algunas industrias y los efectos externos que ello provoca (especialmente en algunas economías del conocimiento); y el tercero es la concentración del capital de ciertos productos financieros que se mantiene en un número reducido de empresas como por ejemplo diversas entidades bancarias.

Todo lo anterior se apoya en un sistema tributario en el que una élite económica se apodera del espacio político e influye en el diseño y aplicación de las políticas fiscales: los ejemplos para muchos de los países de Latinoamérica son múltiples, el caso de México es algo más que un arquetipo.

\section{Informalidad: inversiones y territorios en Latinoamérica}

Las desigualdades sociales se acrecientan a medida que las desigualdades en el desarrollo económico persisten. Estas se han multiplicado a partir del proceso de reordenamiento económico ocurrido en los países y diferentes territorios de Latinoamérica.

Cuando se está invirtiendo en un determinado territorio más que en otros se abren las brechas de las desigualdades y aparecen algunas de estas hasta ese momento desconocidas: de algún modo se está 'fracturando' (fracking) el espacio territorial. Esta fracturación va desarmando el territorio, y a su vez lo rearma de manera diferente, a medida que también va creando enormes contrastes y desigualdades en territorios vecinos o alternos.

Incorporar a un espacio determinados cambios, como en el caso de nuevas inversiones, va configurando gradualmente una nueva estructura espacial que desprovista de un encaje adecuado de políticas públicas, provoca necesariamente otra desigualdad: las nuevas industrias cambian los papeles en las economías regionales. Se acentúan de este modo las diferencias espaciales más allá de las desigualdades espaciales que estaban en su base geográfica (Iglesias 2014, 14-15).

Las inversiones que captan actualmente algunos espacios territoriales en América Latina están destinadas, en buena parte, hacia uno de los ámbitos de mayor importancia para el desarrollo económico: los proyectos de infraestructura que se efectúan en países como Brasil, Colombia, Perú, entre otros. De acuerdo con datos del Banco Mundial, a diferencia de la disminución de las inversiones que se registraron tanto en las potencias emergentes India y China, como en algunos territorios del África subsahariana, durante el 2014 en América Latina y el Caribe se concentró el $55 \%$ de la inversión mundial, lo que representó más de 69 mil millones de dólares. Dicha inversión se compone principalmente de planes de financiamiento para 
megaproyectos, que incluyen 11 proyectos de gran amplitud de los cuales ocho de ellos se desarrollan en el sector energético (D'Almeida 2015, 1).

Algunos analistas han señalado que cerca del $90 \%$ de estos grandes proyectos generan costos superiores a un 50\% de lo establecido en el presupuesto, monto que debe ser absorbido por los contribuyentes de cada país (D’Almeida 2015, 2). Un ejemplo de lo anterior se presentó recientemente, en torno a la construcción de la central hidroeléctrica Manduriacu, en Ecuador, donde el costo final de la obra aumentó en 67,2\% a lo presupuestado originalmente (Villavicencio 2015, 2).

En otro orden de problemas y a pesar de la caída de los precios internacionales de los minerales, el flujo de las inversiones mineras se sigue concentrando en los espacios territoriales latinoamericanos que en el 2014 se constituyen en receptores de $27 \%$ de la inversión para exploración minera global (OCMAL -Observatorio de Conflictos Mineros de América Latina- 2015, 5). En países como Argentina, México, Perú y Chile, la minería ha permanecido entre los sectores con mayor importancia económica en lo que va del siglo XXI, aunque a diferencia de las tres últimas naciones en Argentina se trata de una actividad reciente. No obstante, aunque los emprendimientos mineros a gran escala parecen favorecer en el corto plazo las finanzas de los Estados, sus consecuencias son devastadoras a largo plazo para el medio ambiente, como han demostrado los emprendimientos mineros de empresas como Barrick Gold, en la provincia Argentina de San Juan, o de la Minera San Xavier (subsidiaria de la también canadiense New Gold Inc.), en el estado mexicano de San Luis Potosí.

Los grandes proyectos de infraestructura y minería continúan produciendo importantes beneficios para los capitales que los financian, enriqueciendo aún más a las grandes empresas ya consolidadas y agudizando, a su vez, las condiciones que contribuyen a la ampliación de los bolsones de desigualdad en los territorios a escala global. Si en la década de 1990 la CEPAL marcaba advertencias importantes para los nuevos modelos de desarrollo en América Latina, hacia 2015 no ha habido grandes cambios en la implementación de muchas de estas políticas necesarias para un cambio en la estructura productiva. A partir de entonces la competitividad incluye la sustentabilidad ambiental. La región aún está lejos de incorporar, en una gran mayoría de sus espacios, la biotecnología y la nanotecnología, y otros nuevos materiales para las nuevas TIC. Por otra parte, solo unos pocos territorios se pueden señalar como ejemplos en la utilización de tecnologías limpias para el medio ambiente (OCDE-CEPAL 2013). Actualmente aún se brega por agregar valor intelectual y progreso técnico a la rica dotación de recursos naturales latinoamericanos para que sus exportaciones 'pesen' de otra manera.

Las consecuencias, tanto de los megaproyectos de infraestructura como de minería se expresan esencialmente en las dimensiones macroterritorial y ambiental, ya que no se adecúan a una escala que contemple las características y necesidades de cada población. Tal y como han señalado algunos estudios, estos megaproyectos no solo generan problemas sociales a largo plazo derivados del desplazamiento de las familias que habitan en los espacios en los que se establecen (para luego ser abandonados, en el caso de las minas), sino que también se producen 
impactos ambientales debido a que deterioran los ecosistemas y destruyen la biodiversidad ${ }^{23}$.

En una dimensión económica, estos proyectos proponen la generación de trabajos para la población local, aunque los empleos que generan son principalmente de carácter temporal y en condiciones precarias, por lo que, una vez terminada la obra, los trabajadores se ven obligados a migrar a otros sitios.

A todos estos elementos debemos agregar otros de carácter estructural para analizar uno de los fenómenos que se reflejan con claridad en los espacios de América Latina, a partir de la agudización de las desigualdades: la vulnerabilidad social. Consideramos a esta como un proceso que opera en función de la incertidumbre e inestabilidad a las que cada vez están más expuestos los sectores medios y la población de bajos ingresos, que participan en mercados laborales en los que se observa una constante presencia del desempleo, la persistencia de un amplio sector informal, así como la precariedad laboral que parece configurarse como un rasgo estructural de las economías latinoamericanas.

En la literatura producida por autores como Stampini et al. (2015) o Ferreira et al. (2013), emergen ciertos sectores de una 'nueva clase media' en América Latina como grupos vulnerables ${ }^{24}$ propensos a caer en la pobreza.

A su vez, el crecimiento económico oscilante y la falta de empleos formales ha detonado procesos migratorios, no solo a escala internacional: la población de los antiguos espacios agrarios ha acelerado su desplazamiento hacia las zonas metropolitanas y los centros económicos más importantes en distintos países de Latinoamérica ${ }^{25}$.

En ese marco, las actividades económicas en estos países se han ordenado en función de nuevas estructuras espaciales: por un lado, desde la década de 1990 se ha producido el desarme de determinados sectores industriales y la consiguiente disminución de la población ocupada que anteriormente participaba en estas actividades ${ }^{26}$. Por otra parte, a lo largo del mismo período la tercerización se ha acrecentado, principalmente en aquellos territorios de escaso crecimiento económico y en

23 La otra cara de este fenómeno muestra que actualmente existen en América Latina y el Caribe 218 proyectos mineros implicados en 208 conflictos, que afectan a 312 comunidades de diferentes países en este espacio. México es el país con mayor número de conflictos con un total de 36 (OCMAL 2015).

24 Consideramos que la concepción sostenida por estos autores opaca la realidad latinoamericana en asuntos de formalidad laboral: cada vez se reduce más la cobertura de prestaciones laborales aseguradas por el Estado y se reproducen aceleradamente las formas de ocupación precarias que generan inestabilidad e incertidumbre en torno a la población de diferentes sectores sociales.

25 En países como Brasil, el descenso de la población ocupada en actividades agrícolas se ha observado al pasar de $25 \%$ en 1993 a $14 \%$ en el 2013. En Chile este sector de la población se redujo de $17 \%$ a $9 \%$ entre 1990 y 2013 . En Colombia se ha producido la misma tendencia al reducirse la población ocupada en actividades agrícolas de 25,9\% en 1991 a 16,5\% en 2013. Mientras que en México la población que participa en actividades agrícolas disminuyó de 22\% a 13,3\% entre 1994 y 2010 (CEPALSTAT 2000-2015).

26 La tendencia a la reducción de la población que participa en el sector industrial se ha observado en países como México, Chile y Colombia. En el primer país se redujo de $28 \%$ a $23,5 \%$ en el período 1992-2012; mientras, en Chile la población activa en el sector industrial disminuyó de 28,5\% en 1992 a $24 \%$ en el 2013; en tanto que en Colombia se han registrado oscilaciones pasando de $23,3 \%$ en 1994 a 19,5\% en el 2013 (CEPALSTAT 2000-2015). Sin duda, la disminución más significativa ha ocurrido en los dos primeros países, en los que se venían desarrollando con mayor intensidad las actividades de este sector. 
ciertas ramas de la economía que ocupan mano de obra barata para disminuir sus costos: es el caso de algunas poblaciones del sureste de México.

Los cambios ocurridos en la estructura productiva, en tanto que muchos territorios de la región se insertaron en la economía global, han agravado las asimetrías entre los sectores económicos de mayor y menor productividad, y se ha ampliado la brecha entre ellos. Estos procesos han favorecido la persistencia de la informalidad económica -ya observada anteriormente- la cual venía acrecentándose desde la década de 1990 en diversos espacios de la región (gráfica 4).

Gráfica 4. Población urbana masculina ocupada en el sector informal en América Latina* por categoría ocupacional, 1990-2013

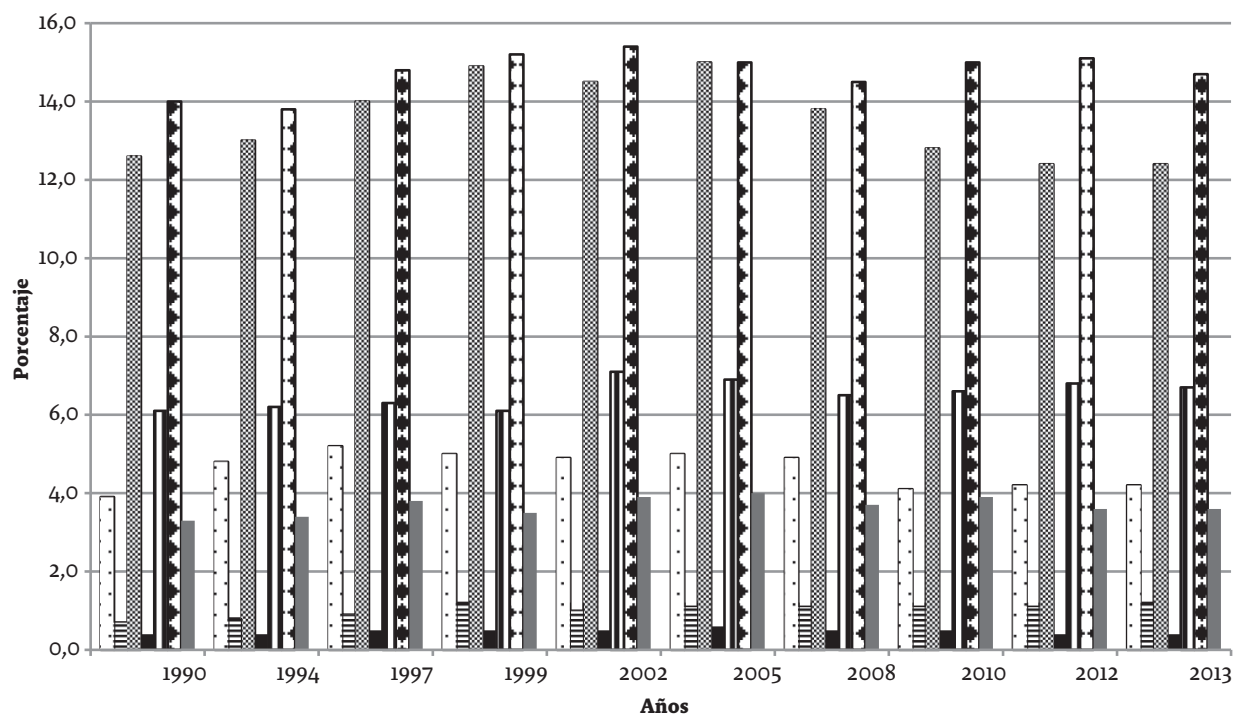

\footnotetext{
[- Microempresa: Empleadores

冈 Microempresa-Asalariados: No profesionales ni técnicos

Trab. Indep. no calificados: Industria y construcción

Trab. Indep. no calificados: Agricultura, ganadería y otros
}

目Microempresa-Asalariados: Profesionales y técnicos

Empleo doméstico

Trab. Indep. no calificados: Comercio y servicios

* Promedio simple.

Fuente: elaborado a partir de datos de CEPALSTAT (2000-2015). Estadísticas e indicadores sociales. Empleo. El número de países considerados varía en algunos años.

La informalidad laboral persiste en los territorios latinoamericanos y se manifiesta, sobre todo, a través del crecimiento de las formas de autoempleo y subempleo en actividades como el comercio y los servicios ${ }^{27}$, donde la población carece del acceso a las mínimas prestaciones laborales y la seguridad social ${ }^{28}$. Esto profundiza

27 Para el caso de Colombia, algunos análisis indican que en el 2005 la tasa de subempleo correspondiente a las personas ocupadas que tienen una jornada menor a 48 horas semanales y desearían trabajar más horas- alcanzó $32,6 \%$ de la PEA, que representaba alrededor de seis millones y medio de personas (Castaño 2007, 24).

28 En México, la vulnerabilidad medida en función del acceso a los servicios médicos registra una segmentación de los servicios de salud. Así, la Encuesta Nacional de Familia y Vulnerabilidad 
la vulnerabilidad social, en la medida en que una gran proporción de la fuerza de trabajo de nuestros países está compuesta por grupos jóvenes que, en muchos casos, cuentan solamente con contrato temporal y a tiempo parcial. Si este problema se contempla a partir del indicador de género se reflejan con mayor nitidez ciertas particularidades que en esta última década se han venido acrecentando. A pesar del crecimiento económico que mostraron los países de América Latina después del 2004, los porcentajes de población masculina incluidos en categorías del sector informal no han disminuido de manera significativa. Los grupos microempresariales de este sector aumentaron de 3,9\% a 4,2\% de 1990 al 2013, mientras que la proporción de los asalariados profesionales y técnicos apenas se incrementó de $0,7 \%$ en 1990 a 1,2\% para ese mismo año. Asimismo, en otras actividades del sector informal tales como comercio y servicios prácticamente la población ocupada osciló alrededor de $14 \%$ entre 1990 y 2013 , y se mantuvo cerca de $12 \%$ para aquellos asalariados sin calificación.

En la otra cara del género ${ }^{29}$, es decir los cambios en los niveles ocupacionales del trabajo femenino informal, que superan la proporción masculina en ciertas categorías, se observa que las llamadas trabajadoras independientes del sector comercio y servicios aumentaron su participación entre 1990 y 2013: de 20,5\% a 22,7\% con un máximo alcanzado en el 2002 de 24,4\%. De esta manera, la mano de obra asalariada femenina mantiene un $8 \%$ de ocupación durante estas últimas dos décadas. Sin embargo, donde las mujeres del sector informal manifiestan un rezago respecto de los hombres es en las actividades microempresarias: de 1,5\% en 1990 apenas alcanzaron 2,3\% en 2013 (gráfica 5).

¿Qué esconden estos datos? Sí reflejan la amplitud de la informalidad laboral en la población femenina de América Latina. Sin embargo, no proyectan la vulnerabilidad generada a raíz de ciertas características culturales de las sociedades latinoamericanas y sobre todo las que aún se insertan en los espacios rurales.

La vulnerabilidad social que rodea a distintos grupos afecta no solo afecta a los sectores de bajos ingresos y nivel educativo básico, sino también a aquellos grupos que pertenecían a cierto estrato socioeconómico medio y que descendieron a causa del desempleo o la inestabilidad laboral ${ }^{30}$.

(2006) mostró que solamente $41,3 \%$ del total de la población contaba con derecho a los servicios de salud que proveen las instituciones de seguridad social, mientras $10,1 \%$ tenía derecho al Seguro Popular y $2 \%$ disponía de un seguro privado. En tanto que casi la mitad de la población no tenía derecho a ningún tipo de servicio médico (46,6\%) (Bayón y Mier 2010, 35).

29 Una característica que consideramos relevante para el análisis es que la participación laboral femenina se observa principalmente en los territorios urbanos. En el caso de México, algunos estudios aportan evidencia de que en el espacio rural solamente $30 \%$ de las mujeres participa en el mercado laboral, en tanto que en el espacio urbano su participación se eleva al 50\% (Bayón y Mier 2010, 80-81).

30 Algunos estudios sobre la incidencia de la vulnerabilidad aportan evidencia empírica sobre el aumento que se ha producido en países como México, al pasar de 0,8481 en 1990 a 1,1534 en el 2010. Por otro lado, a partir del índice de vulnerabilidad también se observa que este fenómeno afecta principalmente a los territorios del sur de este país, sobre todo los estados de Oaxaca, Guerrero y Chiapas, que han mantenido los niveles más altos de vulnerabilidad en el mismo período (Vergara 2011, 94). Por otra parte, la territorialización de la vulnerabilidad también se observa en Brasil, pues a pesar de que el índice de vulnerabilidad social muestra que entre 2000 y 2010 las principales regiones metropolitanas de ese país redujeron sus niveles de vulnerabilidad a un nivel medio $(0,300-$ 0,400 ), se observa la persistencia del fenómeno en los territorios de Manaus (al pasar de 0,560 a 0,415), Grande São Luís (0,551 a 0,395) y Recife (de 0,515 a 0,392) (Costa y Oliveira 2015, 116, 158, 200). 
Gráfica 5. Población urbana femenina ocupada en el sector informal en América Latina* por categoría ocupacional, 1990-2013

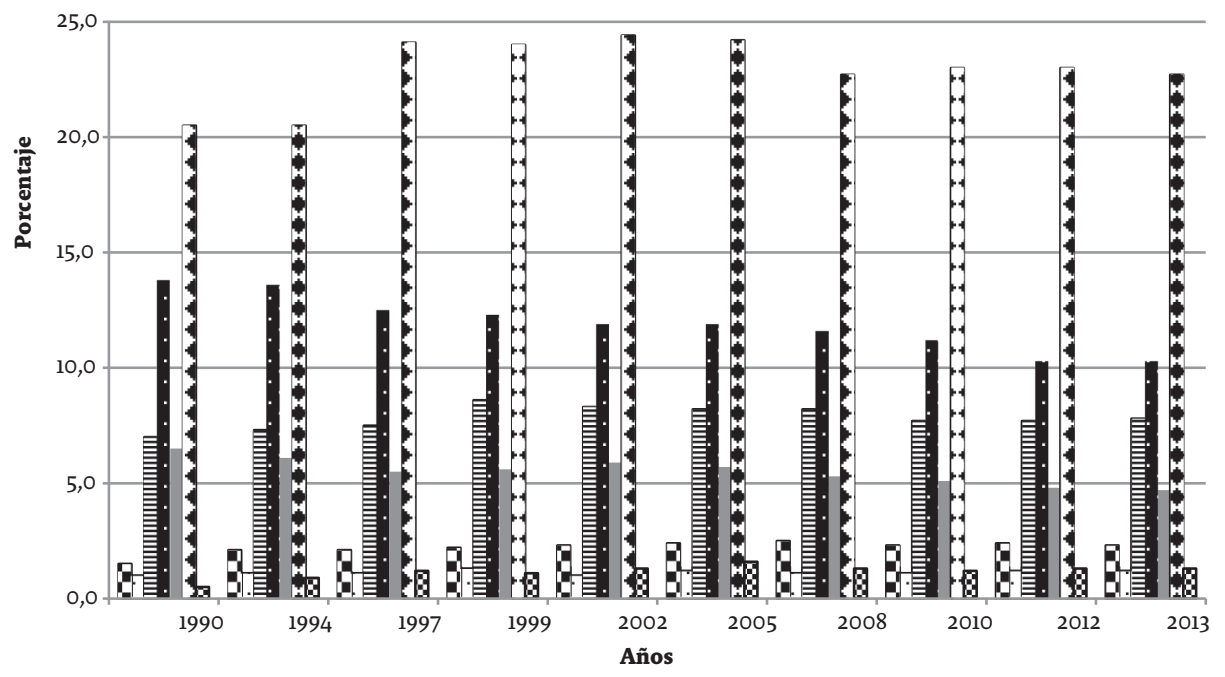

Microempresa: Empleadoras

Microempresa-Asalariadas: No profesionales ni técnicas

Trab. Indep. no calificados: Industria y construcción

Microempresa-Asalariadas: Profesionales y técnicas

Trab. Indep. no calificados: Agricultura, ganadería y otros

Empleo doméstico

Trab. Indep. no calificados: Comercio y servicios

* Promedio simple.

Fuente: elaborado a partir de datos de CEPALSTAT (2000-2015). Estadísticas e indicadores sociales. Empleo. El número de países considerados varía en algunos años.

Los incrementos en el crecimiento económico registrados a lo largo de poco más de una década han podido ser mensurados a través de análisis cuantitativos tomando en cuenta ciertos indicadores, tales como los que aquí hemos registrado. Sin embargo, este crecimiento ha generado cambios de tipo cualitativo que deben ser contemplados en el diseño de nuevas políticas públicas para que se tomen en cuenta las distintas aristas del desarrollo que requieren nuestras sociedades. Estos cambios se pueden observar a partir de determinados comportamientos, aunque aún es difícil evaluarlos sin contar con los indicadores que deberían ser creados para ese efecto.

Hoy y de manera urgente se hacen necesarios estudios de las vulnerabilidades desde una perspectiva cualitativa, para analizar el fenómeno más allá de la mera dimensión económica y alcanzar a trazar las cartas de las brechas y las profundidades creadas en diferentes espacios territoriales considerando los problemas socioculturales.

Recordemos que la vulnerabilidad social no solo ha comenzado a permear a los sectores medios de América Latina revelando sus efectos actualmente de diferentes formas. En ese sentido, se plantea la existencia de nuevas tendencias en la vulnerabilidad que no son muy visibles y su invisibilidad se origina en los alcances limitados de nuestras herramientas analíticas para descubrirlas. 
No ha sido el interés de este artículo proponer caminos alternos para el desarrollo en esta etapa de la globalización económica. Aún quedan por evaluar los graves problemas aparejados por la crisis económica de la actualidad en sus diferentes etapas y dimensiones diversas: habrá que esperar algunas décadas para proyectarla en un tiempo medio, el único capaz de detectar el alcance y consecuencias de los cambios económicos que han afectado a la mayoría de los países en el mundo, pero que en algunas regiones como en el caso de Latinoamérica adquieren determinadas peculiaridades que desembocan en diversas desigualdades. Tal y como propone Touraine (2013), frente a los cambios sociales y culturales que se están generando sí es tiempo, ante todo de:

[...] relacionar el análisis de la crisis con una perspectiva de las transformaciones a largo plazo de la vida social [...] Ciertamente no es la crisis la que engendra un nuevo tipo de sociedad, pero contribuye a la destrucción del tipo de sociedad anterior; puede también impedir la formación de un nuevo tipo de sociedad o favorecer la intervención de actores autoritarios durante un período de transición difícil (Touraine 2013, 13).

En la actualidad estamos contemplando a lo largo y ancho de América Latina las diferentes manifestaciones que ha adquirido la llamada democracia en nuestros países.

La desigualdad es un concepto polisémico y muchas de sus consecuencias no necesariamente se resuelven como recientemente lo consideran ciertos especialistas, moderando los excesos, fortaleciendo el medio y ayudando a los de abajo (Stiglitz 2015, 76). Para nosotros el fenómeno de la desigualdad en esta etapa de la globalización tiene un efecto nuevo en su aceleración: ha venido multiplicándose. Esta multiplicación de las desigualdades podríamos considerarla como hoyos negros que ameritan ser estudiados en sus diferentes dimensiones y escalas comenzando por el análisis cuantitativo que ayudará a construir indicadores más certeros para el tiempo corto. En un futuro estudio para el tiempo medio, este tipo de indicadores complementarían análisis de tipo cualitativo en los que se incorporarían nuevas categorías analíticas. Para ello necesitaríamos generar nuevos indicadores de tipo social y cultural capaces de medir fenómenos de reciente aparición. A partir de ellos, podríamos medir la profundidad y vigencia o alternancia de las desigualdades que hoy apenas hemos señalado como foco de atención.

\section{Reflexiones finales}

- En las décadas de 1950 y 1960 las proyecciones para el desarrollo económico no permitieron ver los alcances cualitativos de este proceso y que en la etapa de la globalización trajo aparejadas consecuencias difíciles de afrontar en la esfera mundial y también en la latinoamericana, tanto en términos económico-sociales como ambientales.

- Las desigualdades y vulnerabilidades han acompañado al desarrollo económico de las sociedades contemporáneas; y se han multiplicado afectando a amplios grupos sociales. Entre otras secuelas, la migración actual en nuestra región es apenas un ejemplo de ello. Desnuda la inexistencia de políticas públicas y los bolsones de deshumanización aguda que hoy se generan y sin que un Estado, ya debilitado, sea capaz de crear nuevos modelos económicos. 
- El adelgazamiento del Estado en América Latina debía estar acompañado de una democratización de los regímenes de gobierno y para ello se debilitaron las finanzas públicas, se redujeron las cargas fiscales con un acrecentamiento de los paraísos fiscales y se crearon nuevos monopolios para repartir cuotas de poder político durante los diferentes gobiernos de turno.

- En términos cepalinos la década del aprendizaje doloroso, la de 1980, habría dejado varias evidencias sobre el modo de incorporación en la región de América Latina de un nuevo modelo de desarrollo.

- A partir de las reformas económicas implementadas en la década de 1990, salvo algunos pequeños espacios territoriales latinoamericanos, en el resto de la región no se compite a partir de agregar valor intelectual y progreso técnico a los recursos naturales. A lo largo de la primera década del siglo XXI, a pesar del aumento en las tasas de crecimiento del PIB no se desarrolló ningún patrón tecnológico necesario e indispensable para una economía sostenible y un nuevo modelo de desarrollo. En muchos países, caso Argentina, se abastece a China, por ejemplo, de soja y de ciertos recursos mineros, entre otros, para cuya explotación no existen leyes protectoras ambientales.

- En tanto que se continúe mensurando el desarrollo a partir del crecimiento económico que permite 'mitigar' la pobreza se proseguirá ocultando las desigualdades que aceleran las diferentes crisis y que retardan la aparición de "nuevas sociedades". No hay que olvidar que los análisis coyunturales no permiten desplegar nuevas categorizaciones, las cuales servirían para dimensionar los alcances de estas transformaciones.

- América Latina tampoco ha avanzado en la estrategia de educación y conocimiento: las evaluaciones internacionales más recientes sobre la calidad de la educación para una gran mayoría de los países latinoamericanos así lo indican.

- Las desigualdades espaciales dentro de los diferentes territorios nacionales se han acrecentado en los últimos decenios. Países como Brasil, Argentina y México son ejemplos arquetípicos. En el caso de México, aquellos territorios que se encuentran en el sur concentran los más altos niveles en cuanto a desigualdades como a vulnerabilidades. En el caso de Brasil y a pesar de que las reformas de políticas sociales transformaron algunos de los contrastes más evidentes en su espacio nacional, persisten aún las desigualdades y vulnerabilidades creadas por este crecimiento económico, que afectan principalmente a las regiones del norte y noroeste de ese país.

- Las nuevas tendencias en la vulnerabilidad se podrían rastrear estudiando con otras herramientas diversos ángulos y dimensiones como: la disposición de servicios de salud para amplios sectores de la población que solamente ofrecen atención para casos de emergencia, pero no para largos tratamientos de enfermedades crónicas o su prevención; en la educación que actualmente se caracteriza por las amplias diferencias en su calidad; en la precariedad de las viviendas a las que familias enteras han tenido que desplazarse para no pagar rentas; la seguridad ciudadana que se ve erosionada en diversos contextos latinoamericanos, donde diariamente se viven situaciones de violencia e inseguridad; y en el caso de la población migrante, es necesario recordar que no se trata solo de una vulnerabilidad migratoria, sino de las diferentes 
formas que adquiere la violencia como ocurre con la posibilidad de adquirir un espacio para habitar, un trabajo y educación, entre otros factores que hacen al bienestar.

\section{Referencias bibliográficas}

Bayón, María y Marta Mier. Familia y vulnerabilidad en México. Realidades y percepciones. México D.F.: IIS-UNAM, 2010.

Brundtland, Gro. Our Common Future. United Nations World Commission on Environment and Development, 1987. https://en.wikisource.org/wiki/Brundtland Report (último acceso: 15 de abril de 2015).

Castaño, Lina. Una aproximación a la vulnerabilidad. Bogotá: Departamento Nacional de Planeación, 2007.

CEPAL (Comisión Económica para América Latina y el Caribe). Cambio estructural para la igualdad: Una visión integrada del desarrollo, 2014. http://www1o.iadb.org/ intal/intalcdi/PE/2014/14144es.pdf (último acceso: 17 de marzo de 2015).

CEPAL. La desigualdad conspira contra las democracias en América Latina y el Caribe, 2015. http://www.cepal.org/es/ccomunicados/la-desigualdad-conspira-contra-las-democracias-en-america-latina-y-el-caribe (último acceso: 10 de abril de 2015).

CEPALSTAT. Base de datos y publicaciones estadísticas, 2000-2015. http://estadisticas. cepal.org/cepalstat/WEB_CEPALSTAT/estadisticasIndicadores.asp?idioma=e (último acceso: 31 de marzo de 2015).

Costa, Marco e Bárbara Oliveira (eds.). Atlas da vulnerabilidade social nas regiões metropolitanas brasileiras. Brasilia: Instituto de Pesquisa Econômica Aplicada, 2015.

Dabat, Alejandro. «Estado, neoliberalismo y desarrollo». En Estado y Desarrollo, de Alejandro Dabat (coord.), 19-64. México D.F.: IIEc-UNAM, 2010.

D’Almeida, Kanya. Infrastructure Investments in Emerging Economies Hit Record Levels- but at What Cost?, 2015. http://www.ipsnews.net/2015/06/infrastructureboom-in-emerging-economies-hits-record-levels-but-at-what-cost/ (accessed: july Ol, 2015).

Espinasa, Ramón, Estefanía Marchán y Carlos Sucre. La nueva ruta de la seda. Patrones emergentes en el comercio de energía y minerales entre Asia y América Latina, 2015. http://publications.iadb.org/handle/11319/6965?locale-attribute=es (último acceso: 15 de junio de 2015).

Esquivel, Gerardo. Desigualdad extrema en México. Concentración del poder económico y político, 2015. http://cambialasreglas.org/images/desigualdadextrema_informe.pdf (último acceso: 15 de junio de 2015).

Fajnzylber, Fernando. Transformación productiva exigida por el cambio tecnológico, 1991. http://repositorio.cepal.org/handle/11362/4604 (último acceso: 20 de abril de 2015).

Ferreira, Francisco, Julian Mesina, Jamele Rigolini, Luis López-Calva, Ana María Lugo y Renos Vakis. La movilidad económica y el crecimiento de la clase media en América Latina, 2013. https://openknowledge.worldbank.org/bitstream/.../9780821397527. pdf (accessed: july ol, 2015)

Freitas, Alexandre. O Brasil real: a desigualdade para além dos indicadores. Sao Paulo: Outras Expressoes, 2012. 
Iglesias, Esther. «Desigualdad espacial y desarrollo territorial del Estado de Yucatán». Pampa, $\mathrm{n}^{\circ}$ 10, 2014: 11-34.

Iglesias, Esther y José Muñoz-Cota. «La desterritorialización del Estado Mexicano: 1976-2009». En Estado y Desarrollo, de Alejandro Dabat (coord.), 195-231. México D.F.: IIEc-UNAM, 2010.

Kaztman, Rubén. Notas sobre la medición de la vulnerabilidad social. Santiago: CEPAL, 2000.

Koch, Martin y Cristina Papaleo. Alemania: ¿desaparece la clase media?, 2012. http:// www.dw.de/alemania-desaparece-la-clase-media/a-16459324 (último acceso: 10 de febrero de 2015).

Londoño, Juan, and Miguel Székely. Persistent poverty and excess inequality: Latin America,1970-1995,1997.http://publications.iadb.org/bitstream/handle/11319/6092/ Persistent\%20Poverty\%20and\%20Excess\%20Inequality\%3A\%20Latin\%20 America,\%201970-1995.pdf? sequence=1 (accessed: april 17, 2015).

Martín, María. «Aprender a vivir con tres horas de agua». El País, España, 11 de mayo, 2015.

Milanovic, Branko. Global Income Inequality by the Numbers: in History and Now. An Overview, 2012. http:/wwwwds.worldbank.org/servlet/WDSContentServer/ WDSP/IB/2012/11/06/000158349_20121106085546/Rendered/PDF/wps6259.pdf (accessed: march 15, 2015).

OCMAL (Observatorio de Conflictos Mineros de América Latina). Conflictos mineros en América Latina: extracción, saqueo y agresión. Estado de situación en 2014, 2015. http://www.conflictosmineros.net/agregar-documento/publicaciones-ocmal/ conflictos-mineros-en-america-latina-extraccion-saqueo-y-agresion-estado-desituacion-en-2014/detail (último acceso: 25 de junio de 2015).

OCDE (Organización para la Cooperación y el Desarrollo Económicos). Divided We Stand: Why Inequality Keeps Rising, 201l. http://www.keepeek.com/DigitalAsset-Management/oecd/social-issues-migration-health/the-causes-of-growinginequalities-in-oecd-countries_9789264119536-en\#page7 (accessed: march 13, 2015).

OCDE. Unemployment rates by education level, 2015. https://data.oecd.org/unemp/ unemployment-rates-by-education-level.htm doi: 10.1787/6183d527-en (accessed: may 4 de 2015).

OCDE-CEPAL. Perspectivas económicas de América Latina 2014. Logística y competitividad para el desarrollo, 2013. http://repositorio.cepal.org/bitstream/ handle/11362/1504/LCG2575_es.pdf;jsessionid=256937CoD3FA0025AFA5691C1A 914B69? sequence=l (último acceso: 03 de marzo de 2015).

OIT (Organización Internacional del Trabajo). Desempleo hombres jóvenes, 2015a. http://datos.bancomundial.org/indicador/SL.UEM.1524.MA.ZS/ countries?display=default (último acceso: 30 de marzo de 2015).

OIT. Desempleo mujeres jóvenes, 2015b. http://datos.bancomundial.org/indicador/ SL.UEM.1524.FE.ZS/countries?display=default (último acceso: 30 de marzo de 2015).

Pérez, Carlota. «La otra globalización: los retos del colapso financiero». Problemas del Desarrollo, Vol. 40, nº 157, 2009: 11-37.

Piketty, Thomas. Le capital au XXIe siecle. Paris: Seuil, 2014.

Requejo, Ferran. Las democracias: democracia antigua, democracia liberal y estado de bienestar. Barcelona: Ariel, 1990. 
Reygadas, Luis. «Las redes de la desigualdad: un enfoque multidimensional». Política y Cultura, $\mathrm{n}^{\circ}$ 22, 2004: 7-25.

Ruiz, Wilfrido. «Desigualdades entre entidades en materia de tecnologías de información y comunicación en México». Realidad, Datos y Espacio, Vol. 6, n ${ }^{\circ}$, 2015: 36-49.

Sassen, Saskia. Expulsiones. Brutalidad y complejidad en la economía global. Buenos Aires: Katz, 2015.

Schatan, Jacobo. Deuda externa, neoliberalismo, globalización. El saqueo de América Latina. Santiago: LOM-Universidad Arcis, 1998.

Stampini, Marco, Marcos Robles, Mayra Sáenz, Pablo Ibarrarán, and Nadin Medellin. Poverty, Vulnerability and the Middle Class in Latin America, 2015. http://wwwlo. iadb.org/intal/intalcdi/PE/2015/15387.pdf (accessed: april 15, 2015).

Stiglitz, Joseph. El precio de la desigualdad. México D.F.: Taurus, 2015.

Therborn, Göran. Inequalities and Latin America. From the Enlightenment to the 21st Century, 2011. http://www.desigualdades.net/Resources/Working_Paper/ WPTherbornOnline.pdf (accessed: february 20, 2015).

Tible, Jean. «¿Una nueva clase media en Brasil? El lulismo como fenómeno político-social». Nueva Sociedad, nº. 243, 2013: 4-17.

Touraine, Alain. «El fin de la ola liberal». En Desigualdad y globalización: cinco conferencias, de Robert Castel, Alain Touraine, Octavio Lanni, Anthony Giddens y Mario Bunge, 29-42. Buenos Aires: Manantial-UBA, 2001.

Touraine, Alain. Después de la crisis. México D.F.: Fondo de Cultura Económica, 2013. Ugarteche, Óscar. «América Latina desde las reformas económicas: acumulación de capital, políticas fiscales y exportaciones». En Capital, crisis y desigualdad en América Latina, de Juan Arancibia (coord.), 61-87. México D.F.: PEL-UNAM, 2010.

Vergara, Reyna. «Vulnerabilidad social y su distribución espacial: el caso de las entidades federativas de México, 1990-2010\%. Paradigma Económico, año 3, nº 2, 2011 : 85-111.

Villavicencio, Arturo. Un cambio de matriz energética bajo toda sospecha, 2015. http:// www.rebelion.org/docs/199476.pdf (último acceso: ol de julio de 2015). 